\title{
Educação em Saúde na escola: conhecimentos, valores e práticas na formação de professores
}

\author{
Tatiane Cristina Possel Greter Schwingel ${ }^{\mathrm{I}, \mathrm{II}}$ \\ Maria Cristina Pansera de Araújo III, IV
}

https://dx.doi.org/10.24109/2176-6681.rbep.102i261.3938

\section{Resumo}

Universidade Regional do Noroeste do Estado do Rio Grande do Sul (Unijuí). Ijuí, Rio Grande do Sul, Brasil. E-mail:<tgschwingel@ gmail.com $>$; $<$ https://orcid org/0000-0001-5823-4473>.

II Doutora em Educação nas Ciências pela Universidade Regional do Noroeste do Estado do Rio Grande do Sul (Unijuí). Ijuí, Rio Grande do Sul, Brasil.

III Universidade Regional do Noroeste do Estado do Rio Grande do Sul (Unijuí). Ijuí, Rio Grande do Sul, Brasil. E-mail:<pansera@ unijui.edu.br $>$; $<$ https:// orcid.org/0000 -0002 $-2380-6934>$

Iv Doutora em Genética e Biologia Molecular pela Universidade Federal do Rio Grande do Sul (UFRGS) Porto Alegre, Rio Grande do Sul, Brasil.

Neste artigo, procurou-se ampliar os estudos sobre a Educação em Saúde (ES) na escola, articulando questões relativas à formação docente e às estratégias de desenvolvimento conceitual em saúde nos currículos. A proposição foi verificar quais conhecimentos, valores e práticas têm sido evidenciados nas produções científicas acerca da ES na escola no que se refere à formação de professores. O estudo considerou a produção acadêmica em artigos científicos, teses e dissertações, indexados na Coordenação de Aperfeiçoamento de Pessoal de Nível Superior (Capes) e na Base de Dados Digital da Universidade do Minho (Portugal), entre os anos de 2014 e 2019. Para compreensão do corpus analítico, foi utilizada a Análise Textual Discursiva (ATD) (Moraes; Galiazzi, 2014), de modo a identificar as unidades de significado dos textos. Assim, este estudo realizou uma revisão narrativa crítica da literatura, fundamental para problematizar a temática e compor a justificativa de escolha do tema para a pesquisa e sua constituição. Por meio das observações emergidas da investigação, pode-se inferir que os conhecimentos, os valores e as práticas se entrelaçam, no processo de empoderamento do sujeito sobre a ES, indicando que o cuidado de si, a promoção da vida saudável e da prevenção de doenças não acontece de maneira individual, fragmentada ou simplesmente prescritiva. No entanto, 
a investigação também revelou que essa articulação permanece limitada quanto à inserção nas matrizes curriculares das escolas.

Palavras-chave: concepções de saúde; currículo; formação docente; modelo KVP; produção científica.

\section{Abstract \\ Health education at school: knowledge, values and practices in teacher training}

This article aims to expand the studies on Health Education (HE) at school, articulating issues related to teacher training and strategies of conceptual development in health in the curricula. The proposition was to verify which knowledge, values and practices have been gaining prominence in the scientific productions related to $\mathrm{HE}$ at school regarding teacher training. The study has looked into academically produced articles, theses and dissertations indexed in the Coordination for the Improvement of Higher Education Personnel (Capes) and in the Digital Database of the University of Minho (Portugal), from 2014 to 2019. To understand the analytical corpus, Discursive Textual Analysis (DTA) (Moraes; Galiazzi, 2014) was used, aiming to identify the meaning units in the texts. Thus, this study conducted a critical narrative review of the literature, which is fundamental to discuss the subject and to draft the justification for choosing the theme for the research and its constitution. Through observations gathered from the investigation, it can be inferred that knowledge, values and practices are intertwined with the empowerment of the subject about HE, which indicates that self-care, promotion of a healthy life and the prevention of diseases does not happen individually, in a fragmented or simply prescriptive way. However, the research also revealed that this articulation remains limited in terms of syllabus in schools.

Keywords: curriculum; health conceptions; KVP model; scientific production; teacher training.

\section{Resumen \\ Educación para la Salud en la escuela: conocimientos, valores y prácticas en la formación de profesores}

En este artículo, se ha buscado expandir los estudios sobre la Educación para la Salud (EPS) en la escuela, relacionando las cuestiones correspondientes a la formación docente y las estrategias de desarrollo conceptual en salud en los currículos. La intención ha sido examinar cuales conocimientos, valores y prácticas han sido evidenciados en las 
producciones científicas en relación a la EPS en la escuela en lo que se refiere a la formación de profesores. Este estudio ha considerado la producción académica en artículos científicos, tesis de doctorado y disertaciones, indexados en la Coordinación de Perfeccionamiento de Personal de Nivel Superior (Capes) y en la Base de Datos Digitales de la Universidad de Minho (Portugal), entre los años de 2014 hasta 2019. Para la comprensión del corpus analítico, ha sido utilizado el Análisis Textual Discursivo (ATD) (Moraes; Galiazzi, 2014), de manera a identificar las unidades de significado de los textos. Por consiguiente, esta investigación ha realizado una revisión narrativa crítica de la literatura, hecho fundamental para problematizar la temática y componer la justificación de la elección de la temática para la investigación y constitución. Por medio de las observaciones surgidas, se ha podido deducir que los conocimientos, valores y prácticas se entrecruzan en el proceso de empoderamiento del sujeto sobre la EPS, señalando que, el cuidado de si, la ascensión a la vida saludable y la prevención de las enfermedades no ocurren de modo individual, fragmentado o sencillamente prescriptivo. A pesar de ello, la investigación también ha revelado que esa articulación ha permanecido limitada cuanto a la inserción en las matrices de los currículos de las escuelas.

Palabras clave: concepción de salud; formación docente; modelo KVP; plan de estudio; producción científica.

\section{Aspectos introdutórios}

A Educação em Saúde (ES), entendida por Candeias (1997) como conjunto de ações educativas voltadas à tomada de consciência e de atitudes que levem à promoção da saúde e à prevenção de doenças, fundamenta o desenvolvimento da ES na escola por meio de conceitos como o autocuidado, a prevenção de doenças e a promoção da saúde (Saboga-Nunes et al., 2016).

A educação escolar tem, entre outros propósitos, o de discutir e desenvolver conceitos relacionados à saúde. Assim, organiza ações educativas voltadas a garantir a aprendizagem em saúde dos estudantes. O professor, em seu processo formativo profissional, define e esclarece os propósitos educativos da ES na escola, torna possível sugerir e adotar caminhos na caracterização dos currículos escolares, de forma a levar conhecimentos promotores de vida saudável aos estudantes.

Contudo, escolas e professores podem encontrar dificuldade em organizar suas ações educativas em torno do tema Saúde, na aprendizagem dos estudantes, frente ao que seria Educação em Saúde no currículo das escolas. Essas dificuldades para desenvolver temas de saúde em sala de aula podem decorrer da pouca abordagem da temática nos cursos de formação inicial. Isso se percebe nas legislações educacionais, como a Lei de Diretrizes e Bases para a Educação (LDB) (Brasil, 1996) e os Parâmetros Curriculares Nacionais (PCNs) (Brasil. MEC, 1997a, 1997b, 
1997c), que defendem a necessidade de sensibilizar os professores para que promovam as mudanças necessárias na educação básica, sugerindo alterações curriculares e atualização. Ainda, recentemente estabelecida, a Base Nacional Comum Curricular (BNCC) sugere habilidades e competências de ensino e aprendizagem, de encontro às dimensões de ES.

A intenção de realizar uma revisão da literatura sobre o tema se justifica na medida em que as diferentes abordagens são percebidas, além de identificar dimensões que ainda não foram contempladas. Diante disso, os estudos sobre a ES na escola, articulando questões relativas à formação docente e às estratégias de desenvolvimento conceitual em saúde, nos currículos escolares, produziram reflexões sobre os conhecimentos, os valores e as práticas desenvolvidos nas publicações analisadas.

O movimento da ES, no contexto da escola e do trabalho educativo do professor, torna-se desafio na elaboração das ações pedagógicas que sejam promotoras de conhecimentos, valores e práticas de vida saudável junto aos estudantes. Essa produção de saberes acerca da ES no contexto da escola pressupõe debates, reflexões, postura competente e problematizadora por parte dos docentes. Assim, com base nos aspectos destacados, a proposição deste artigo é verificar quais conhecimentos, valores e práticas têm sido evidenciados nas produções científicas acerca da ES na escola no que se refere à formação continuada de professores.

\section{Estado do conhecimento como encaminhamento metodológico}

O estudo considerou a produção acadêmica sobre a ES na escola e a formação de professores, manifestada em artigos científicos, teses e dissertações, indexados na Coordenação de Aperfeiçoamento de Pessoal de Nível Superior (Capes), utilizando o Catálogo de Dissertações e Teses e o Portal de Periódicos, e na Base de Dados Digital da Universidade do Minho (UMinho) (Portugal), com seis repositórios de acesso livre, entre os anos de 2014 e 2019.

A metodologia utilizada foi um mapeamento da produção científica em torno de alguma temática de pesquisa, visto que permite reconhecer fragilidades teóricas e conceituais, bem como problemáticas emergidas nas produções já publicadas. Logo, a metodologia propicia uma contextualização do divulgado, novas reflexões e entendimentos para estudos posteriores. Para Mayer (2007), o processo de revisão da produção científica em torno de um tema/área contempla uma organização.

[...] levantamento da bibliografia e das informações contidas na mesma, de acordo com os objetivos da pesquisa; leitura crítica do pesquisador acerca destas informações para explicar, discutir, justificar os fatos e informações contidas no material pesquisado. (Mayer, 2007, p. 43).

Para a constituição deste artigo, a revisão da literatura ocorreu em caráter analítico e qualitativo das publicações sobre a temática, com o descritor "Educação em saúde e Formação continuada de professores", para os textos contidos nas bases de dados brasileiras e portuguesas. 
A investigação resultou em 232 documentos, sendo 184 correspondentes ao Portal Capes e 48 ao Portal UMinho, que foram posteriormente acessados e transferidos para a ferramenta de análise Atlas Ti7.

A ferramenta Atlas Ti7 é um software de análise de dados em larga escala, que permite examinar grande quantidade de textos e organizar os fragmentos significativos. Devido às suas características e ao grande volume textual a ser analisado, essa ferramenta foi utilizada para otimizar o tempo e para dar confiabilidade às análises emergidas. Na análise de conteúdo do material coletado, os textos identificados foram examinados com o objetivo de reconhecer as seguintes categorias de análise: conhecimentos, valores e práticas.

Para a constituição do corpus analítico, foi utilizada a Análise Textual Discursiva (ATD) (Moraes; Galiazzi, 2014), de modo a identificar as unidades de significado existentes nos textos. Essa metodologia possibilita analisar os documentos produzidos, por meio da interpretação da estrutura textual, promovendo compreensões acerca dos dados apresentados.

A ATD constitui-se em um meio de melhorar as compreensões dos fenômenos investigados ao longo das análises realizadas nos metatextos produzidos na pesquisa. É assim entendida por incluir "[...] desde a análise de discursos num extremo, até a análise de conteúdo num outro limite." (Moraes; Galiazzi, 2014, p. 7). Assim, corresponde a uma análise metodológica de origem qualitativa de objetos diversos, com intenção de possibilitar novos entendimentos a respeito dos discursos e dos conteúdos a eles associados, em que "[...] a intenção é a compreensão, reconstruir conhecimentos existentes sobre os temas investigados" (Moraes; Galiazzi, 2014, p. 11).

Os parâmetros aqui utilizados para a coleta e a análise dos textos publicados serviram para delinear aspectos emergentes em torno do tratamento da ES na escola e na formação docente, que foram concentrados em mapas conceituais que inter-relacionam conceitos-chave em torno dos conhecimentos, dos valores e das práticas em saúde na escola. Cabe destacar que a produção dos mapas conceituais se deu a partir da ferramenta Coggle, um aplicativo livre de mapeamento mental disponível para uso da web.

\section{Conhecimentos, valores e práticas na Educação em Saúde}

O tratamento analítico dos dados expressa argumentos, palavras e conceitos que permitem traçar elementos que constituem os processos de ensino, formação e prática dos professores em relação à ES na escola.

Para a interpretação das unidades de significado dos textos selecionados, utilizou-se como critérios de análise o Modelo KVP: interações entre conhecimentos, valores e práticas sociais, proposto por Clément (2004, 2006). Esse modelo considera a interação entre os conhecimentos, os valores e as práticas para a definição do trabalho pedagógico em torno da saúde. Essa interação é fundamental e intrínseca por complexificar os conceitos e as estratégias de promoção da saúde na escola. Para Clément 
(2006, p. 27), "classificar os três pólos, $\mathrm{K}, \mathrm{V}$ e P, assim como as suas possíveis interações, é um pré-requisito para a melhoria do ensino das Ciências, em particular da Educação para a Saúde", sendo que

[...] o conhecimento (K) refere-se à informação proveniente da comunidade científica. Os valores (V) são neste modelo assumidos num sentido lato do termo, incluindo opiniões, crenças e ideologias. Por exemplo, o sexismo, o racismo ou a xenofobia são considerados como valores, assim como a procura da verdade pela ciência e as 'ideologias científicas' definidas pelo epistemologista Cangulihem (1977) para caracterizar as tendências no âmbito das ciências biológicas, como o reducionismo, a anatomização ou o absoluto determinismo genético. As Práticas sociais (P) referem-se às dos actores do sistema educacional: as práticas de ensino dos professores, as práticas dos autores e editores de manuais escolares, incluindo as suas concepções relacionadas com as práticas sociais actuais e futuras dos estudantes a que se dirigem; não só o seu futuro profissional, mas principalmente a sua responsabilidade de actuais e futuros cidadãos. (Carvalho; Clément, 2007, p. 3).

Nessa perspectiva, os conhecimentos $(\mathrm{K})$ podem se apresentar de maneira científica, técnica e/ou cultural. As práticas (P) estão relacionadas àquelas produzidas historicamente e estabelecidas pela sociedade, e os valores $(\mathrm{V})$ podem expressar as concepções de um grupo quanto ao que se toma como verdadeiro e correto. Clément (2006) considera que as práticas e os valores são passíveis de maiores debates sobre suas definições, pois, para os diferentes sujeitos (professor, escola, aluno e sociedade), as visões e as formações epistemológicas diferem, suscitando internalizações e interpretações variadas. As definições para conhecimentos, valores e práticas assemelham-se e aproximam-se quanto às características e finalidades, em que as concepções de cada sujeito são permeadas por seus $\mathrm{K}, \mathrm{V}$ e P.

Pensando no contexto do ensino em relação à saúde, é importante definir o que se espera da escola como instituição formal de aprendizagens. A sociedade estabelece expectativas nesse sentido e, para Araújo, Emmel e Cambraia (2016), a função da ES na escola gira em torno de perspectivas diversas ao interagirem e definirem estratégias promotoras de vida saudável.

A educação em saúde propõe o cuidado de si e dos outros, na interação entre diferentes sujeitos, objetivando a prevenção de doenças, a promoção da saúde e a melhoria na qualidade de vida. Para que o sujeito assuma tais atitudes, necessita estar alfabetizado cientificamente e sensibilizado para tomar decisões favoráveis à manutenção da saúde. (Araújo; Emmel; Cambraia, 2016, p. 109).

No entanto, quando se fala da abordagem da saúde na escola, é impossível pensar somente na perspectiva do conhecimento, pois não basta isso para mudar a prática pedagógica e as atitudes de cada sujeito. $\mathrm{O}$ contexto social, cultural e de valores dos grupos interfere na constituição do sujeito (Vigotski, 2007), que se torna um fenômeno social, com desenvolvimento da capacidade de aprender e viver na interação com o outro. Para intervir na realidade, o indivíduo precisa compreender como ela está funcionando, para além de saber, simplesmente, os conceitos 
científicos. A partir dessas afirmações, como movimentar-se na escola para assegurar a Educação em Saúde? Que aprendizagens de saúde constituem pressupostos nas intencionalidades fundantes da escola? Qual o lugar da ES, na ordem simbólica, em que se institui o sujeito? O que significa a ES no contexto social e cultural dos sujeitos? Que conhecimentos são necessários para entender e fazer Educação em Saúde na escola? Será que o contexto da sala de aula/escola é suficiente para aprender sobre saúde? Como o social interfere para que o aluno se mobilize a querer aprender/ saber sobre saúde? Como ensinar ciências numa perspectiva da educação em saúde, que ultrapasse a visão reducionista de estudo dos ciclos de vida e prevenção de doenças?

Com certeza, encontrar respostas a cada um desses questionamentos não é simples, uma vez que os processos de ensinar e aprender são complexos e dinâmicos, assim como as abordagens de saúde requerem perspectivas de autonomia e empoderamento na formação do sujeito aprendente. Assim, valida-se a importância da interação entre K, V e P, em que, para SabogaNunes et al. (2016, p. 59), "Esta dinâmica inclui, igualmente, o currículo formal e informal em saúde, a criação de um ambiente escolar saudável, a prestação de serviços de saúde apropriados e o envolvimento da família e comunidade ampliada nos esforços promotores de saúde".

Também, uma das alternativas para tornar o trabalho didático sobre a saúde mais problematizador é a construção de um projeto político pedagógico para a escola, que seja validado pelo diálogo, pois ele "é proposta ético-política, isto é, articulação da natureza intersubjetiva da formação da vontade coletiva" (Marques, 1993, p. 9) e revela como os sujeitos entendem o processo educativo. E na realização deste documento que se discute a questão ética ou dos valores, definindo que cidadão e que sociedade, no que diz respeito à saúde, a escola propõe formar, com intenções definidas, compartilhadas, organizadas, numa condução administrativa, pedagógica e democrática.

Nesse mesmo contexto, os currículos promotores de saúde na escola são aqueles que, ao interagir, promovem não só a articulação entre os $\mathrm{K}, \mathrm{V}$ e P, mas também a reflexão sobre os conhecimentos publicados e reconhecidos na sociedade. Clément (2006, p. 25) aborda isso ao destacar as intencionalidades do modelo KVP "[...] analisar quais os valores e as práticas sociais que podem retardar ou acelerar a aceitação dos conhecimentos científicos novos. O polo K pode assim, segundo o contexto, referir-se a conhecimentos científicos ultrapassados ou, pelo contrário, atualizados". A comunicação entre as dimensões de K, V e P no tratamento da saúde na escola permite perceber a evolução e a renovação dos conceitos. A interação serve para avaliar que $\mathrm{V}$ e $\mathrm{P}$ podem acelerar ou retardar a aceitação de conhecimentos científicos novos, para além daqueles instituídos historicamente. Os conhecimentos científicos evoluem e se renovam na medida em que o contexto $\mathrm{K}, \mathrm{V}$ e $\mathrm{P}$ interagem.

Quanto aos textos analisados, podemos inferir o contexto em que se inserem as discussões em torno da ES na escola, em âmbito nacional e internacional, fundamentados nos diferentes repositórios estudados (Capes/Brasil e Repositório UMinho/Portugal). Em ambas as bases de dados investigadas, as produções nacionais se referem ao cenário brasileiro 
e português, e as internacionais, aos textos de outra nacionalidade. Destacamos ainda que, nas distintas bases de dados, a produção internacional remeteu, exclusivamente, a textos do tipo artigo científico. Os critérios de análise iniciaram com a busca das palavras conhecimentos, valores e práticas de saúde na escola, no repertório das publicações, que propiciaram identificar várias abordagens e significados, problematizando a interação entre eles.

Objetivando configurar os perfis e as tendências que a produção levantada aponta em relação ao tratamento do tema da Educação em Saúde, na formação continuada dos professores, analisamos os seguintes aspectos nos textos: $i$ ) as pesquisas no contexto do Brasil e de Portugal se aproximam quanto às definições de formação e à ação pedagógica em saúde; ii) os entendimentos teóricos se revelam nas pesquisas investigadas acerca dos $\mathrm{K}$, V e P em saúde no currículo escolar; iii) a transversalidade entre $\mathrm{K}$, V e P em saúde interfere na formação e na atuação pedagógica docente.

Este estudo analítico da produção levantada, entre artigos, dissertações e teses (232 trabalhos), não teve como proposição principal realizar aferições quantitativas de maneira a contabilizar os textos de cada uma das categorias, uma vez que importava reconhecer e sistematizar cenários e elementos ainda não pontuados entre as produções científicas e que contribuem para a caracterização do perfil das produções. Assim, utilizando o software Atlas Ti7 para análise, foi possível considerar o texto completo dos trabalhos selecionados pelas bases de dados para identificar as unidades de significado que constituíram as categorias. Tais unidades foram criadas a priori e identificadas por análise interpretativa do conteúdo: conhecimentos, valores e práticas.

Com base na revisão analítica dos textos selecionados, com a palavra conhecimentos foram identificados sete subgrupos temáticos, os quais denominamos: Sujeitos, Ações, Características, Tipos, Impacto, Lugares e Implicações.

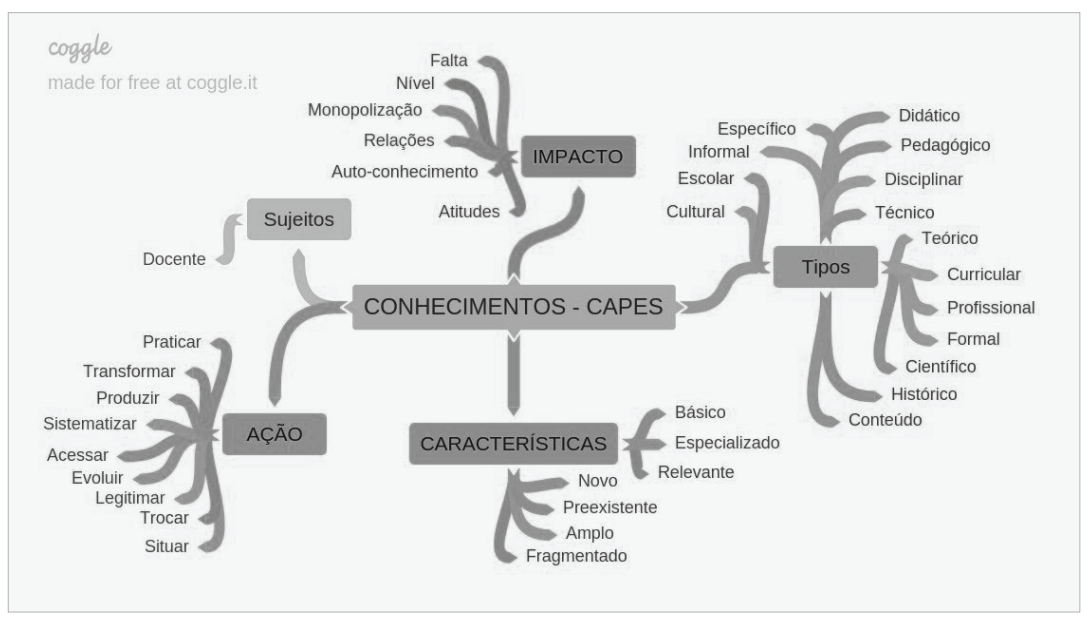

Figura 1 - Mapa conceitual produzido com base na análise dos trabalhos indexados no Portal Capes

Fonte: Elaboração própria. 
Conforme os mapas, verificamos que os textos dos portais Capes e UMinho possuem alguns subgrupos temáticos que se assemelham (Sujeitos, Ações, Características, Tipos) e outros em que diferem (Impacto, Lugares, Implicações). É importante considerar também que, mesmo nos subgrupos em que se aproximam, os temas que emergem de cada um não são os mesmos. Ainda comparando ambos, os mapas se tornam singulares à medida que percebemos, na produção internacional, uma maior contextualização da categoria conhecimentos, ao estabelecer uma diversidade de elementos que se desdobram em temáticas acerca das relações que a categoria estabelece dentro dos discursos presentes nas produções científicas investigadas.

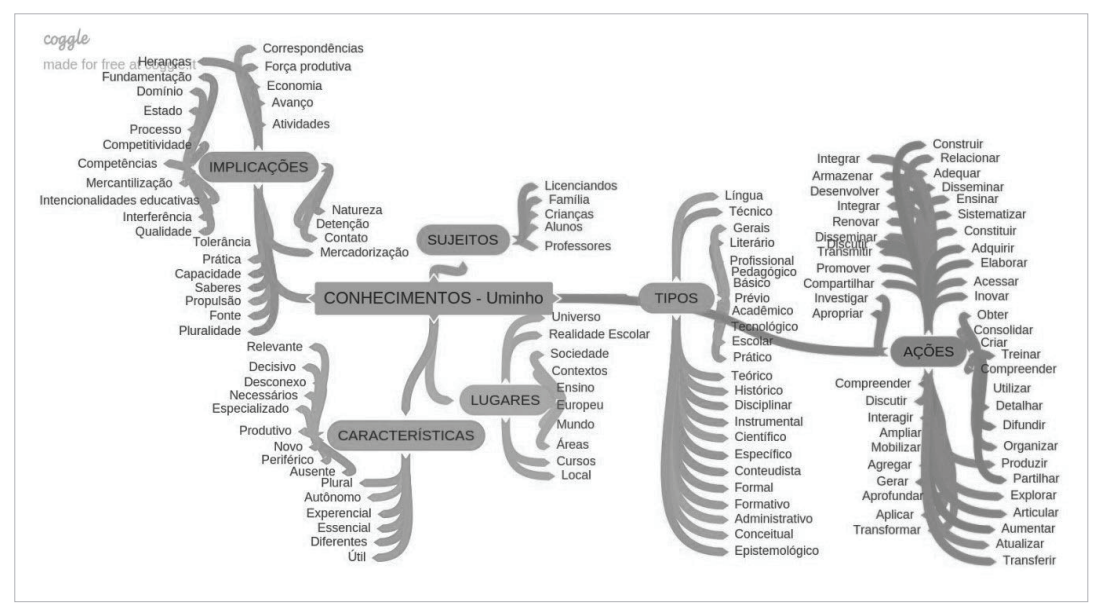
Figura 2 - Mapa conceitual produzido com base na análise dos
trabalhos indexados no Portal UMinho

Fonte: Elaboração própria.

Em relação ao subgrupo temático "tipos" de conhecimentos, os textos dos portais Capes e UMinho estabelecem uma série de associações referentes à natureza/origem que o conhecimento pode apresentar no currículo escolar em saúde na escola, perpassando desde um conhecimento do tipo básico e elementar até um conhecimento especializado. A respeito dessa apresentação do conhecimento, Mayer (2007) considera que este se apresenta de diferentes formas, problematizando contextos e questões, no processo de investigação científica, como: i) a construção do conhecimento; ii) a organização do conhecimento; iii) a (re)elaboração do conhecimento; e iv) a socialização do conhecimento.

Gonçalves e Gonçalves (1998), ao falarem sobre o professor e seus conhecimentos, destacam a concepção de Shulman (1986) para os saberes docentes. Essa definição assumida pelos autores também perpassa pelas formas e/ou tipos de conhecimentos, sendo, nesse caso: de conteúdo, pedagógico e curricular. O primeiro se refere à área na qual o professor é especialista; o segundo diz respeito à adequação do conhecimento aos públicos e níveis de ensino; e, por fim, o terceiro trata do conjunto de conceitos e conteúdos a serem considerados nos currículos escolares para efetivar a aprendizagem dos estudantes. 
Shulman (1986) ainda classifica o conhecimento quanto à sua forma de apresentação no processo educativo, sendo: i) proposicional - aquele sem significado e relação com o mundo do estudante; ii) de caso - aquele útil, problematizador e articulador da teoria e da prática; e iii) estratégico aquele que se manifesta e se adquire no contexto da prática de sala de aula.

Acerca do que Shulman (1986) classifica como um conhecimento que se apresenta de forma útil, podemos verificar que, nos mapas construídos com base nos textos analisados, a questão de um conhecimento que seja ou se torne de utilidade/relevante para a vida do sujeito em sociedade aparece associado ao subgrupo temático "características". Essa inferência acerca de um conhecimento útil perpassa pelo viés de ter como característica desse conhecimento a capacidade de tornar os conceitos significativos e relacionados à vida cotidiana dos sujeitos, conforme Young (2007) define, "conhecimento poderoso".

Sobre a indagação "o que o indivíduo recebe na escola?", Young (2007, p. 1293) propõe de "que [ou qual] conhecimento? E, em particular, questiona que tipo de conhecimento é responsabilidade da escola transmitir". A partir dessa premissa, Young (2007) traz a ideia de "conhecimento poderoso" referindo-se ao que o conhecimento pode fazer, e que "alguns tipos de conhecimento são mais valiosos do que outros, e as diferenças formam a base para a diferenciação entre conhecimento curricular ou escolar e conhecimento não-escolar" (Young, 2007, p. 1294).

Sobre a importância desse conhecimento poderoso para a sociedade, uma vez que "tanto no presente quanto no passado nosso ideal pedagógico é, até em seus menores detalhes, obra da sociedade" (Young, 2007), Savater (1998, p. 61) compartilha com esta ideia e argumenta que a arte de ensinar a aprender consiste em formar fábricas, e não armazéns. Utilizando as ideias de Juan Delval (apud Savater, 1998, p. 62),

[...] uma pessoa capaz de pensar, de tomar decisões, de buscar a informação relevante de que necessita, de se relacionar positivamente com os outros e cooperar com eles é muito mais polivalente e tem mais possibilidades de adaptação do que quem só tem formação específica.

Young (2007) também compartilha com Savater (1998) e reflete a respeito ao dizer que o conhecimento poderoso não está disponível em casa, configurando-se assim como o conhecimento especializado que buscamos e encontramos nas escolas. Com isso, percebemos que "a escola - ou, para sermos mais prudentes, as formas institucionalizadas de educação - devem, em síntese, formar não apenas o núcleo básico da personalidade" (Savater, 1998, p. 63), ou seja, as instituições de ensino têm um papel educacional complexo, que dinamiza sua tarefa de ensinar, pois "a educação é uma tarefa de sujeitos e sua meta é formar também sujeitos, não objetos nem mecanismos e precisão [...]" (Savater, 1998, p. 172).

Young (2007, p. 1297), na mesma linha de pensamento, também defende que o conhecimento escolar é e deve ser diferente do não escolar, assim como a base em que é feita essa diferenciação, de forma que as 
escolas possam refletir: "Este currículo é um meio para que os alunos possam adquirir conhecimento poderoso - conhecimento especializado?". Essa preocupação do autor em definir os conhecimentos escolares e não escolares também é ressaltada nas produções analisadas, quando nos mapas conceituais remete-se como tipos de conhecimentos diferentes o formal e o informal. E, conforme Young (2007, p. 1297) completa, "não há nenhuma utilidade para os alunos em se construir um currículo em torno da sua experiência, para que este currículo possa ser validado e, como resultado, deixá-los sempre na mesma condição".

Cabe destacar que os elementos destacados por Mayer (2007) (construir, organizar, (re)elaborar) também se evidenciam nos mapas, no que se refere às "ações" para com o conhecimento. Especificamente em relação a esse subgrupo temático, os textos analisados remeteram-se a muitas ações importantes e/ou imprescindíveis para a tarefa educativa em saúde na escola. Uma delas, em especial apontada por ambos os mapas, trata do conhecimento pelo viés da transformação. Acerca disso, Zanon et al. (2007, p. 139) apontam que

A educação que se busca vem aliada a um repensar transformador das
mentalidades, das próprias formas de conceber, de produzir e de lidar
com o conhecimento escolar, como inter-relação dinâmica entre formas
cotidianas e científicas de linguagem e conhecimento, que devem fazer
parte dos novos diálogos que ainda estamos aprendendo juntos a tecer.

Ao pensar o currículo como promotor da ES, aliado ao conhecimento, percebemos a capacidade de este se comportar como agente de transformação não só da vida do sujeito aprendente, mas também da sociedade na qual ele se insere. Assim, essa apropriação conceitual em saúde se apresenta no contexto do processo de construção, exploração e construção do conhecimento, em que "a exploração do conhecimento pela investigação possibilita a emergência de questões relacionadas com o objeto de estudo, conhecer as produções já realizadas na área e corroborar para o processo de (re)elaboração e ampliação do conhecimento" (Mayer, 2007, p. 41).

Outra ramificação inserida no subgrupo temático "ações" refere-se ao conhecimento aliado a um processo de interação entre os conhecimentos produzidos e estabelecidos pelas comunidades científicas e/ou culturais. Conne (1996, p. 233), a esse respeito, demonstra que tal interação se revela quando

[...] os investigadores deixam de se contentar com um interesse exclusivo pelo funcionamento e pelo desenvolvimento cognitivo de um indivíduo isolado, e passam a pretender examinar de que forma estes assumem o seu lugar no seio de interações de diversos sujeitos implicados numa mesma situação.

Para ele, o ensino procede da interação dos conhecimentos de um professor com os conhecimentos de um aluno, que visa fazer assentar os conhecimentos do aluno em saberes (Conne, 1996, p. 223). 
A respeito dessa mesma questão, Gauthier e Martineau (2001, p. 65) corroboram que "os alunos não somente aprendem uns com os outros, mas sua relação com o saber será em parte determinada pela dinâmica da classe", isso porque, para os autores, a sala de aula é como uma microssociedade, em que cada indivíduo busca ajustar as suas crenças e os seus comportamentos em função dos outros.

Ou seja, aqui o saber não é tido mais como um bem de propriedade individual, mas, sim, comum, de construção e reconstrução em grupo. Conne (1996) compartilha com a ideia, afirmando que o conhecimento de um dado sujeito é cognitivamente interativo com o conhecimento de outro sujeito, o que explica o fato de que o conhecimento de outro seja acessível ao nosso próprio conhecimento.

Conne (1996) revela ainda que esse conhecimento oferecido por alguém para que alguém aprenda coloca o aprendiz em situações que o fazem pensar os conhecimentos e reconhecer seu papel ativo sobre a situação com que se depara e vice-versa. Desse modo, um conhecimento assim identificado é um saber e um conhecimento utilizável, porque permite ao sujeito agir sobre a representação. Assim, "o saber é um conhecimento que controla uma situação e as suas transformações, elas próprias indutoras de conhecimentos. Em muitos casos, saber é saber colocar-se em situação de mobilizar os próprios conhecimentos para agir" (Conne, 1996, p. 238).

A temporalidade de regência da ordem do conhecimento e a dos saberes, para Conne (1996), é diferenciada, pois "enquanto, há uma constituição cognitiva de invariantes operatórias, estabilização, a longo prazo, os saberes estão sempre disponíveis, isto é, são remetíveis para situações próximas" (Conne, 1996, p. 236).

A partir disso, Conne (1996, p. 238) propõe uma dinâmica particular de interação dos conhecimentos, em que ao professor cabe "aproveitar judiciosamente a interação cognitiva que consegue manter com os seus alunos e a situação que ela lhe propõe, a fim de ativar o desenvolvimento dos seus conhecimentos", fazendo com que "esse conhecimento que se desenvolve e esses saberes que dele se destacam assumam a forma de saberes constituídos que ele tem que ensinar!" (Conne, 1996, p. 238).

Para Conne (1996, p. 240), o conhecimento nem sempre é transmissível, mas o saber, sim, pois a utilidade deste é transformar as situações. Dessa maneira, a transposição de saber ou a utilização do conhecimento ocorre "quando um saber transferido de uma situação para a outra conserva, relativamente a este novo quadro situacional, o seu caráter de saber (isto é, o seu caráter reconhecido de transformador da situação)".

Diante do mapeamento das questões, em relação à categoria valores, 14 subgrupos temáticos se constituíram: Prática, Saúde, Afirmações, Quantitativos, Éticos, Culturais, Abstrato, Conhecimento, Humanos, Coisas, Lugares, Tipos, Características e Ações. 


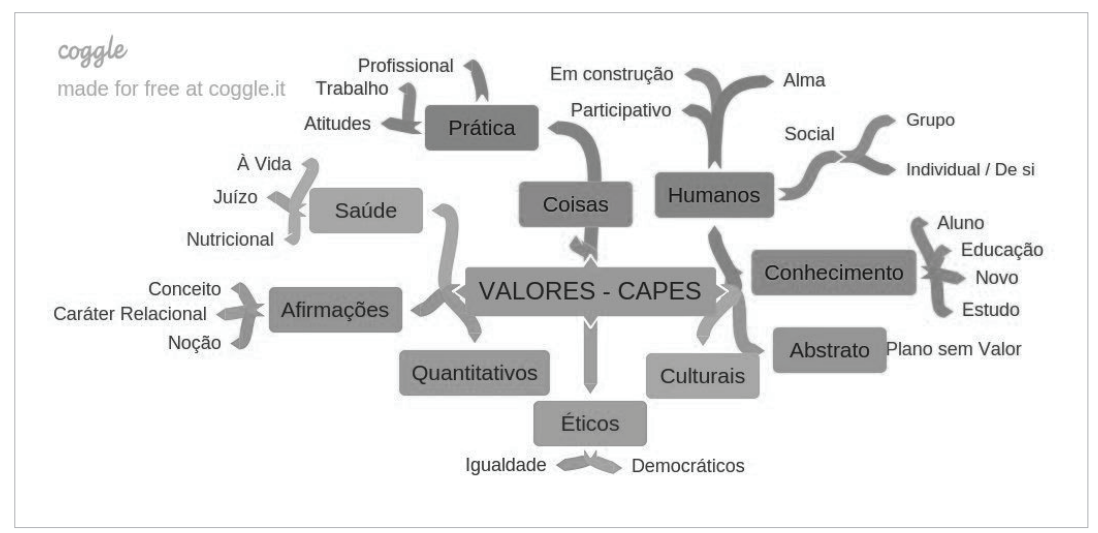

Figura 3 - Mapa conceitual produzido com base na análise dos trabalhos indexados no Portal Capes

Fonte: Elaboração própria.

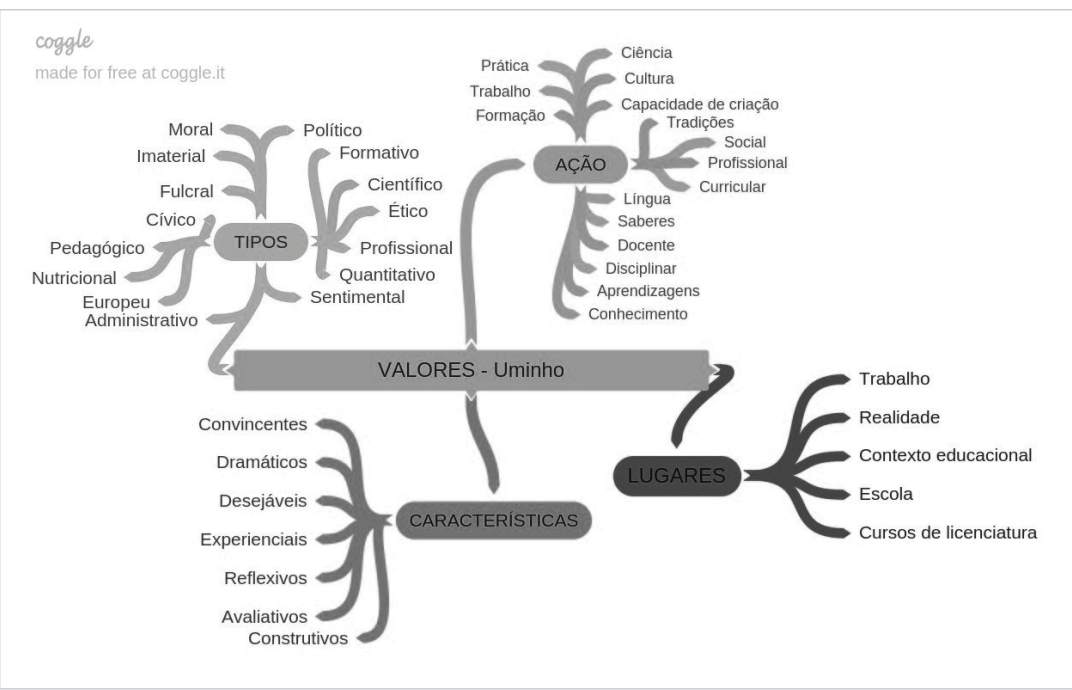

Figura 4 - Mapa conceitual produzido com base na análise dos trabalhos indexados no Portal UMinho

Fonte: Elaboração própria.

Com base no exposto nas Figuras 3 e 4, o que se percebe é que os mapas da categoria valores são aqueles em que os textos não conseguem estabelecer tanta reflexão argumentativa, visto que o quantitativo de elementos advindos é mais otimizado. Pode-se aferir que os textos dos portais Capes e UMinho não possuem nenhum subgrupo temático com mesma denominação, no entanto, as ramificações emergidas se aproximam quanto às suas intencionalidades argumentativas, como a exemplo dos valores humanos destacados no Portal Capes e os valores do tipo moral e éticos do Portal UMinho. Sobre os referidos tipos de valores destacados pelos textos analisados, Clément (2006, p. 26) os define a partir dos direitos universais, em que 
A Declaração Universal dos Direitos do Homem é uma ilustração que clama, por exemplo, a igualdade de direitos de todos os seres humanos, e denuncia, portanto, os valores que se opõem, como o sexismo e o racismo. Os valores de cidadania ou republicanos (tais como liberdade, igualdade, fraternidade, laicismo, mas também respeito, tolerância, [...] são muitas vezes tidos como referências.

Olhando para a história da educação em termos cronológicos e epistêmicos, percebemos uma forte dimensão racista ou sexista presente nos currículos escolares, conforme ressaltado por Clément (2006). Isso porque, sendo a escola uma instituição de ensino voltada aos interesses da sociedade, por muito tempo ela esteve atrelada a concepções e valores superados e considerados ultrapassados nos dias de hoje.

Sobre isso, Guillot (2008) argumenta que as missões institucionais perpassam por instruir o saber a ser adquirido pelos alunos, educar socializando valores e cidadania e formar no sentido da inserção profissional. Com isso, demonstra que saber as competências a serem ensinadas já não basta mais, uma vez que "ensinar não se reduz a saber fazer diante de seus alunos, mas a saber fazer com que estes façam" (Guillot, 2008, p. 125).

Ambos os mapas construídos a partir da análise dissertam sobre os "tipos" de valores existentes e que permeiam o contexto educativo em saúde. Para as produções científicas indexadas ao Portal Capes, os "tipos" de valores destacados são humanos, culturais e éticos, sendo que o Portal UMinho também discute acerca dos valores morais, porém amplia a abordagem desse subgrupo temático ao estabelecer outras relações, como valores do tipo imaterial, nutricional e profissional.

Ainda acerca dos "tipos" de valores, nessa categoria de análise, ambos os portais, a partir dos seus textos indexados, consideram o social como importante definidor das estratégias de Educação em Saúde na escola, sendo que as produções relativas ao Portal Capes especificam a constituição do social pelo viés coletivo e/ou individual.

Embora seja sabido que os valores interferem na constituição dos currículos e nas práticas escolares em saúde, sejam eles éticos, morais, culturais e/ou sociais, a forma como uma criança se socializava há 20 anos é diferente de hoje. Isso muito tem a ver com os agentes socializadores que se estabeleceram ao longo do tempo e que acabam por modificar os interesses e as finalidades das ações pedagógicas em relação à saúde.

As propostas de ensino e aprendizagem sobre saúde na escola estão intimamente associadas aos entendimentos dos professores sobre o que é Educação em Saúde e promoção da saúde na escola. A esse respeito, observando os mapas emergidos, no Portal UMinho, verificamos pela abordagem dos valores do tipo pedagógico uma relação com essa proposta educativa em saúde, assim como no Portal Capes, que traz afirmações acerca do conceito e do caráter dos valores em saúde escolar. 
Dessa forma, considerando as concepções formativas dos professores sobre ES como definidoras das estratégias curriculares, torna-se fundamental desarmar o que o professor considera saber de saúde para então conseguir constituir novas possibilidades de entendimento, até porque a concepção de ES que um professor tem pode ser diferente da de outro professor, em função dos processos sociais que os constituíram e os fizeram crer nisso, ou seja, possui estreita relação com seu processo formativo. Clément (2006, p. 27), sobre esse aspecto destacado, afirma que "dificuldades no ensino são muitas vezes devidas ao fato de o professor não partilhar os mesmos valores e/ou práticas sociais dos seus alunos, embora ele pense que tais dificuldades devem-se apenas aos conteúdos científicos a ensinar".

Com base nessas pontuações acerca do que as publicações em torno do tema de investigação deste artigo estão considerando para a categoria valores na ES, fica claro o entendimento de que a escola precisa oferecer espaço para que o sujeito reflita e se torne capaz de estabelecer relações que entretecem a sociedade no que diz respeito ao tema da saúde, respeitando suas condições e necessidades. Nessa perspectiva, a educação não unifica os sujeitos em relação às suas diferenças e não assegura o respeito frente às suas individualidades culturais e/ou sociais.

No tocante à categoria práticas de ES, observadas nos textos investigados, identificaram-se oito subgrupos temáticos: Sujeitos, Ações, Características, Tipos, Implicações, Relações, Conflitos e Lugares.

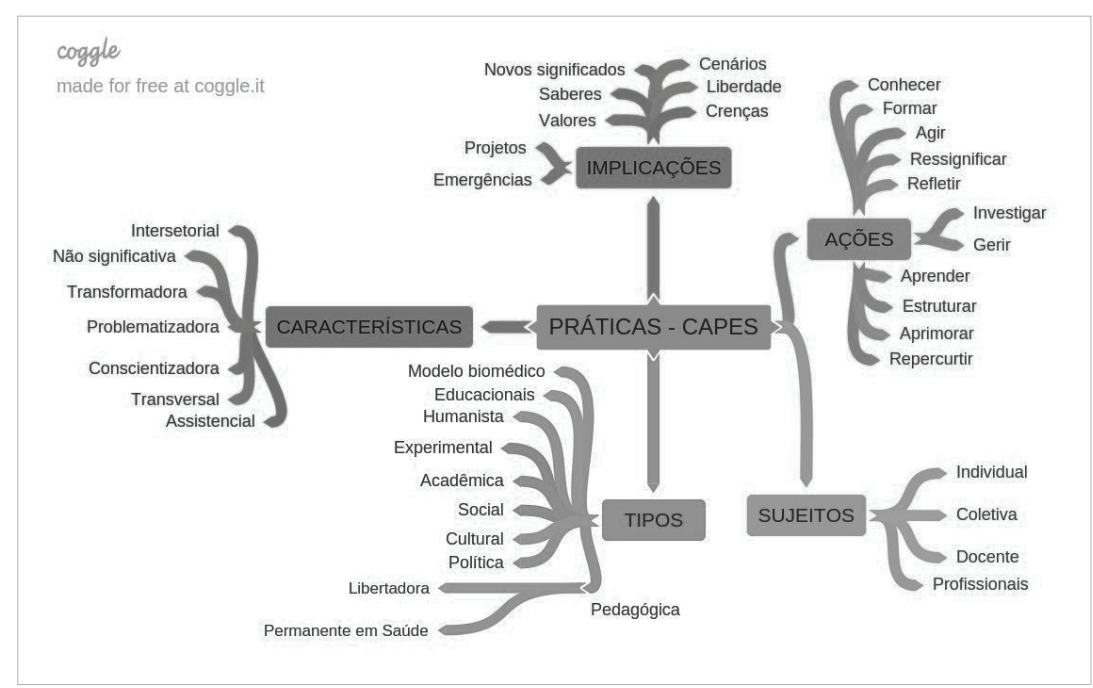

Figura 5 - Mapa conceitual produzido com base na análise dos trabalhos indexados no Portal Capes

Fonte: Elaboração própria. 


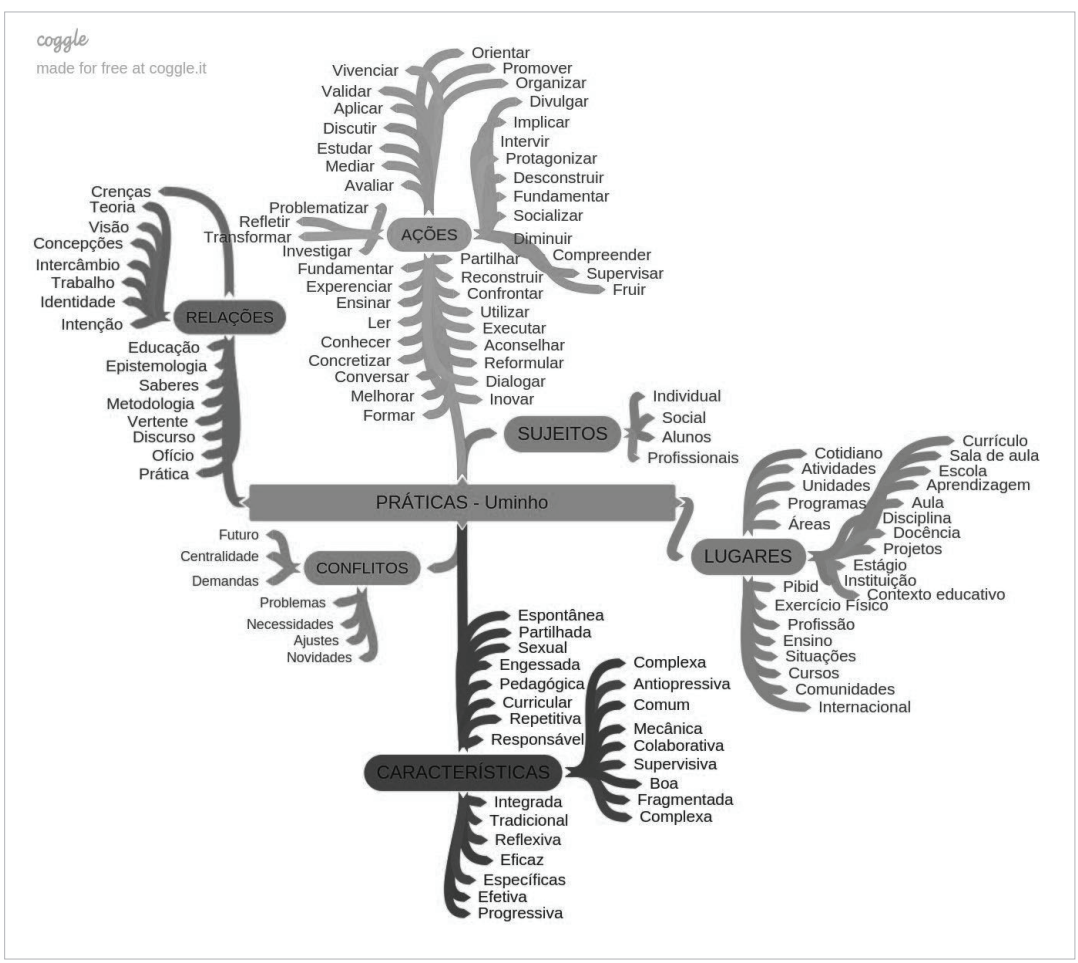

\section{Figura 6 - Mapa conceitual produzido com base na análise dos trabalhos indexados no Portal UMinho}

Fonte: Elaboração própria.

A respeito das informações expressas nos mapas, observa-se que os textos dos portais Capes e UMinho possuem alguns subgrupos temáticos que se assemelham (Sujeitos, Ações e Características) e outros que se diferem (Tipos, Relações, Conflitos, Lugares e Implicações). Assim como verificado na categoria conhecimentos, as ramificações emergidas para o mesmo subgrupo são diferentes em cada um dos portais.

Ainda relacionado à categoria conhecimentos, nesta foram ressaltados os saberes docentes e sua importância na constituição da formação e da ação pedagógica. Da mesma forma, essa preocupação também surge na categoria práticas, em que os textos chamam a atenção para esse aspecto, a exemplo do verificado pelas ramificações argumentativas dos subgrupos temáticos "implicações" e "relações" nos mapas Capes e UMinho (Figuras 5 e 6). Para Boff e Zanon (2014, p. 134),

[...] compreende-se a importância da articulação dos saberes acadêmicos com os saberes da prática cotidiana de sala de aula, para que sejam desencadeadas propostas de ensino inovadoras e que tenham o professor de escola como parceiro na produção do currículo escolar.

A questão da reflexão da prática docente também foi ponto de destaque e discussão entre as diversas linhas temáticas emergidas da análise das publicações. O mapa do Portal Capes aborda esse aspecto formativo a partir 
do subgrupo temático "ações", ao destacar conceitos formativos como: ressignificar, refletir e aprimorar. Acerca disso, cabe destacar que a prática da reflexão da ação por parte do professor é defendida por muitos autores e estudos em relação ao contexto educacional, relacionando esta ação principalmente à formação continuada docente, em que as intencionalidades pedagógicas são constantemente re(avaliadas) no fazer docente. Conforme Zanon et al. (2007, p. 139),

[...] rever nossas posturas, nossas rotinas e a própria racionalidade da qual decorrem os modos como relacionamos as teorias com as práticas, na vida cotidiana que se faz, nem sempre nas sintonias nem harmonias, mas nas discordâncias e inquietações que a própria vida nos impõe.

A partir disso, não há como separar as práticas de ES da formação docente, seja ela inicial ou continuada. Acerca dessa premissa, o Portal UMinho, para a categoria práticas, estabelece relação do tratamento do tema da saúde escolar e curricular ao processo formativo docente, quando, no subgrupo temático "lugares", discute elementos como: Pibid, estágio, projetos e programas permanentes em saúde. Essa dimensão defendida pelos textos analisados permite considerar possibilidades e alternativas para qualificar os espaços e tempos de formação docente no que se refere ao tratamento do tema da ES na escola.

Gonçalves e Gonçalves (1998) consideram um desafio para a formação dos professores a necessidade de superar uma formação docente centrada no modelo da racionalidade técnica, sem a problematização da prática. Os autores percebem como fragilidade a falta de práticas na formação inicial docente,

[...] em que o estudante universitário possa ter contato com o ambiente escolar, tendo contato com os alunos e a complexidade que lhe é natural, uma vez que a prática de ensino vigente é, em geral, insuficiente para lhes proporcionar essa experiência reclamada. (Gonçalves; Gonçalves, 1998, p. 115).

Sobre a ação pedagógica, as publicações científicas estudadas e associadas ao Portal Capes revelam, a partir do subgrupo temático "tipos", duas formas de estratégia profissional do sujeito professor: a libertadora ou a permanente em saúde. Essas definições caracterizam uma prática docente complexa e problematizadora da realidade do indivíduo. Assim, a definição das atividades educativas em saúde na escola possui uma intencionalidade pedagógica contextual.

Nessa perspectiva, surgem as práticas do social como influenciadoras do trabalho pedagógico em saúde na escola. Acerca disso, o Portal Capes, por meio de seus textos, discute que o desenvolvimento conceitual em ES seja feito a partir do que foi socialmente construído e estabelecido, em que a discussão sobre o currículo em saúde se dê em torno da escola de educação básica em consonância com a comunidade em que está inserida, proporcionando uma promoção da autonomia e do empoderamento do sujeito diante das problemáticas advindas de seu cotidiano a partir da transformação ativa de seus conhecimentos e saberes. 
Para isso, porém, torna-se essencial considerar uma constante relação entre teoria e prática na formação e na atuação docente. O Portal UMinho, dentro dos subgrupos temáticos "relações" e "características", assume a teoria como articulada de maneira integrada à prática para um ensino em saúde na escola. Nesse sentido, uma ação pedagógica com característica assistencial e setorial não cumpre com o esperado para um trabalho educativo socializador e promotor de vida saudável aos sujeitos.

\section{Considerações finais}

Com a discussão dos resultados, explicitando particularidades e linhas investigativas sobre o campo formativo docente em ES na escola, podem ser demarcadas tendências e problemáticas, que, por sua vez, definem o contexto no qual se inserem as publicações científicas analisadas neste estudo. Os elementos identificados no material empírico constituem o conhecimento acerca da temática proposta e revelam lacunas e fragilidades, que passam a permitir e demandar novas investigações acadêmicas.

O estudo apresentado, baseado em um breve mapeamento da produção científica em torno da Educação em Saúde na escola, permitiu estabelecer a constituição teórica das publicações revisitadas quanto aos conhecimentos, aos valores e às práticas imbuídos na formação de professores. Por meio da leitura dos textos e da produção dos mapas conceituais, foi possível reconhecer a formação e a atuação do professor na interação entre os conhecimentos, os valores e as práticas na ES, como complexificação da função educadora, nos currículos escolares.

Revisitando os materiais deste estudo, evidenciaram-se aproximações entre Brasil e Portugal, no que diz respeito à formação docente e consequente produção curricular em saúde. Fica institucionalizada, no cenário brasileiro e português, a relação de interdependência entre $\mathrm{K}$, V e P para o desenvolvimento da ES na escola, numa perspectiva problematizadora dos saberes.

Os resultados, de modo geral, indicam que pensar e desenvolver o tema da saúde no contexto educativo de maneira a considerar o trabalho pedagógico somente por um dos aspectos, sejam conhecimentos, ou valores, ou práticas, é impossível, à medida que esses conceitos se relacionam entre si. Esse aspecto pressupõe, então, uma transversalidade da ES nas matrizes curriculares.

A partir das propostas de investigação das pesquisas analisadas e do reconhecimento dos grupos temáticos problematizados, no contexto das discussões, foi possível identificar quais conhecimentos, valores e práticas são evidenciados na formação de professores sobre a ES e, a partir disso, identificar a convergência entre os textos e a necessidade da interação, articulação e internalização desses aspectos para o tratamento do tema, no fazer pedagógico em saúde. Assim, considerando essa interlocução conceitual entre os textos, parecem ficar claras a possibilidade e a necessidade da interação dialógica entre conhecimentos, valores e práticas na ação educativa do tema da saúde. 
Por meio das observações surgidas das publicações investigadas, pode-se inferir que os conhecimentos, os valores e as práticas se entrelaçam no processo de empoderamento do sujeito sobre a ES, indicando que a promoção da vida saudável não acontece de maneira individual, fragmentada ou simplesmente prescritiva. Ambos os textos reforçam a concepção de uma ES integradora do sujeito em seus aspectos biopsicossociais, em que os conceitos de saúde são produzidos na interação com o coletivo.

Ao mesmo tempo, essa investigação também revela que essa articulação entre conhecimentos, valores e práticas na ES, identificada na produção científica mapeada, permanece limitada quanto à efetivação dessa interação nas matrizes curriculares das escolas. Os resultados apontam lacunas e distanciamentos entre os estudos produzidos e a prática adotada, na tarefa educativa com o tema da ES na escola.

Dessa forma, frente às questões apontadas, consideramos que a natureza dessas fragilidades da ação educativa com o tema da ES na escola, de modo a integrar os conhecimentos, os valores e as práticas, reside principalmente na formação dos professores, que se inicia nos cursos de formação inicial, mas que deve permanecer ao longo da carreira docente, por meio da formação continuada. Logo, reconhecemos também que os critérios de investigação e as categorias definidas neste estudo poderiam ainda ser mais aprofundadas e comparadas, quando da utilização de questões mais específicas de análise.

Ao final, entendemos que a produção deste artigo permitiu fazer um levantamento e uma análise crítica a respeito do tema da ES e da interação entre conhecimentos, valores e práticas na formação continuada de professores, em diversos contextos de investigação científica e acadêmica. Este estudo caracteriza uma revisão narrativa crítica da literatura, fundamental para problematizar a temática e apontar novas pesquisas.

\section{Referências}

ARAÚJO, M. C. P.; EMMEL, R.; CAMBRAIA, A. C. Aproximações e distanciamentos dos currículos de ciências biológicas e computação: um espaço-tempo para educação em saúde. In: BOFF, E. T. O.; ARAUJO, M. C. P.; CARVALHO, G. S. (Org.). Interações entre conhecimentos, valores e práticas na educação em saúde. Ijuí: Editora Unijuí, 2016. p. 109-132.

BOFF, E. T. O.; ZANON, L. B. Interações de professores em formação inicial e continuada articuladas com processos de reconstrução curricular em coletivos escolares. In: NERY, B. K.; MALDANER, O. A. (Org.).

Formação de professores: compreensões em novos programas e ações. Ijuí: Editora Unijuí, 2014. p. 133-157.

BRASIL. Lei no 9.394, de 20 de dezembro de 1996. Estabelece as diretrizes e bases da educação nacional. Diário Oficial da União, Brasília, DF, 23 dez. 1996. Seção 1, p. 27833. 
BRASIL. Ministério da Educação (MEC). Parâmetros Curriculares Nacionais: apresentação dos temas transversais. Brasília, DF: MEC/SEF, 1997a.

BRASIL. Ministério da Educação (MEC). Parâmetros Curriculares Nacionais: ciências naturais. Brasília, DF: MEC/SEF, 1997b.

BRASIL. Ministério da Educação (MEC). Parâmetros Curriculares Nacionais: meio ambiente, saúde. Brasília, DF: MEC/SEF, 1997c.

CANDEIAS, N. M. F. Conceitos de educação e de promoção em saúde: mudanças individuais e mudanças organizacionais. Revista de Saúde Pública, São Paulo, v. 1, n. 2, p. 209-13, abr. 1997.

CARVALHO, G. S.; CLÉMENT, P. Projecto "Educação em biologia, educação para a saúde e educação ambiental para uma melhor cidadania": análise de manuais escolares e concepções de professores de 19 países (europeus, africanos e do próximo oriente). Revista Brasileira de Pesquisa em Educação em Ciências, Belo Horizonte, v. 7, n. 2, p. 1-21, maio/ago. 2007.

CONNE, F. Saber e conhecimento na perspectiva da transposição didática. In: BRUN, J. (Org.). Didáctica das matemáticas. Lisboa: Instituto Piaget, 1996. p. 219-267.

CLÉMENT, P. Science et idéologie: exemples en didactique et en épistémologie de la biologie. [Lyon, 2004]. Disponível em: <http:// sciences-medias.ens-lyon.fr/IMG/pdf/Clement.pdf>. Acesso em: ago. 2020.

CLÉMENT, P. Didactic transposition and KVP model: conceptions as interactions between scientific knowledge, values and social practices. Braga: ESERA Summer School; Universidade do Minho, 2006.

GAUTHIER, C.; MARTINEAU, S. Triângulo didático-pedagógico: o triângulo que pode ser visto como um quadrado. Revista Educação nas Ciências, Ijuí, v. 1, p. 45-77, jan./jun. 2001.

GONÇALVES, T. O.; GONÇALVES, T. V. O. Reflexões sobre uma prática docente situada: buscando novas perspectivas para a formação de professores. In: GERALDI, C. M. G.; FIORENTINI, D.; PEREIRA, E. M. A. (Org.). Cartografias do trabalho docente: professor (a) - pesquisador (a). Campinas: Mercado de Letras, 1998. p. 105-134.

GUILLOT, G. O resgate da autoridade em educação. Porto Alegre: Artmed, 2008.

MARQUES, M. O. Proposta político-pedagógica da escola: uma construção solidária. Espaços da Escola, Ijuí, v. 8, p. 9-16, 1993. 
MAYER, E. O processo de investigação na pesquisa científica: investir na busca, seguindo o rastro do conhecimento. In: GALIAZZI, M. C. et al. (Org.). Construção curricular em rede na educação em ciências: uma aposta de pesquisa na sala de aula. Ijuí: Editora Unijuí, 2007. p. 39-52.

MORAES, R.; GALIAZZI, M. C. Análise textual discursiva. 2. ed. rev. Ijuí: Editora Unijuí, 2014.

SABOGA-NUNES, A. L. et al. Níveis de alfabetização/literacia para a saúde em duas populações de diferentes níveis de escolaridade na construção da cidadania. In: BOFF, E. T. O.; ARAÚJO, M. C. P.; CARVALHO, G. S. (Org.). Interações entre conhecimentos, valores e práticas na educação em saúde. Ijuí: Editora Unijuí, 2016. p. 57-88.

SAVAteR, F. O valor de educar. São Paulo: Martins Fontes, 1998.

SHULMAN, L. S. Those who understand: knowledge growth in teaching. Educational Researcher, [Washington], v. 15, n. 2, p. 4-14, Feb. 1986.

VIGOTSKI, L. S. A formação social da mente: o desenvolvimento dos processos psicológicos superiores. 7. ed. São Paulo: Martins Fontes, 2007.

YOUNG, M. Para que servem as escolas? Educação \& Sociedade, Campinas, v. 28, n. 101, p. 1287-1302, set./dez. 2007.

ZANON, L. B. et al. Saberes e práticas em interação num processo interdisciplinar de reconstrução curricular em uma escola de ensino médio. In: GALIAZZI, M. C. et al. (Org.). Construção curricular em rede na educação em ciências: uma aposta de pesquisa na sala de aula. Ijuí: Editora Unijuí, 2007. p. 120-141.

Recebido em 25 de outubro de 2019.

Aprovado em 20 de março de 2021. 